\section{Internet pharmacy: prices on the up-and-up}

$\mathrm{E}_{\mathrm{p}}^{\mathrm{n}}$ nter the name of a popular prescription drug in an Internet search engine and you will quickly grasp just how big the Internet pharmacy market is in Canada. A large proportion of sales are to US customers, who are estimated to purchase upward of US\$1 billion in drugs per year from Canadian pharmacies. Americans are turning to Canadian pharmacies with good reason: for many of them, Canadian retail prices for brand-name prescription drugs are a bargain. But, even in this era of free trade and regulatory harmonization, many American policy-makers are opposed to such bargain hunting. Although their opposition generally revolves around a purported concern with public safety, the underlying objections are clearly rooted in protecting the industry's profitability. In doing so, policy-makers are supporting pricing strategies that ultimately harm uninsured and underinsured Americans.

Despite the fault-seeking missions of US regulators (see page 946), the safety and quality of Canadian drugs cannot be the core of this issue. Because the most efficient way to produce drugs is in large facilities that serve multiple markets, many brand-name prescription drugs sold in Canada and the US are manufactured in the same plants. In 2002, drug "manufacturers" in Canada imported approximately $\$ 3.9$ billion worth of materials from the US. These included finished products that are simply packaged in Canada for sale through Canadian pharmacies. Thus, those in the US who order Canadian drugs are mainly reimporting American-made drugs with Canadian packaging.

Nor can contact with pharmacists and prescribing doctors be a principal concern in this debate. Mail-order pharmacy has become the fastest growing component of the American market without sparking "public safety" concerns. In fact, its growth has been spurred on by incentives that major drug benefit providers give patients to use lower-cost distribution channels. That the mail-order dispensary, staffed by similarly licensed pharmacists, is north of the 49th parallel renders the practice no less professional.

The real reason American access to low-cost drugs from Canada constitutes a "problem" is because it undermines a profitable pricing strategy of branded pharmaceutical manufacturers. This strategy is to segment the drug market (both by jurisdiction and by purchaser within a jurisdiction) such that different prices can be charged to different purchasers. Such price discrimination, as every undergraduate economics student learns, is the most effective way to maximize profits.

Leading economists are quick to point out that international price discrimination results in prices that appear to be in proportion with national incomes. ${ }^{1}$ Prices in the US are highest, so the reasoning goes, because average incomes are highest in the US. However, this ignores the fact that markets are segmented not only across countries, but also within countries. Moreover, price discrimination strategies are constrained not only by the buyer's ability to pay, but also by the buyer's ability to negotiate. If ability to pay were the sole basis on which drug companies set prices, Canadian prices would be slightly lower than those in the US, but prices for uninsured Americans would be among the lowest in North America.

Canadian drug prices are certainly lower than US retail prices. But there are two prices (at least) in the US market: a "retail" price, and a discounted price for large drug plans. Large US purchasers such as insurance companies and government plans leverage the buying power of millions of beneficiaries to negotiate undisclosed price discounts from drug manufacturers. The bulk of these discounts do not take place at retail. Rather, substantial discounts come in the form of payments made directly from the manufacturer to the insurance company or government agency. Just as a dealership will not disclose the negotiated price given on your neighbour's new car, hiding drug price discounts is essential to the practice of segmenting the market according to negotiating power. When discounts are taken into account, the average price paid by large US purchasers is certainly lower than the average Canadian retail price. Otherwise, the large US drug benefits managers and insurance companies would be lining up alongside the uninsured to buy their drugs from Canada.

To date, only groups with limited price negotiating power, mostly the uninsured and some states whose negotiating power is constrained by federal law, ${ }^{2}$ have sought price relief in Canada. They do so with good reason: when these groups purchase drugs within their own country, they actually subsidize the drug purchases of major insurance companies.

The most influential purchasers in Canada - the provincial drug benefit plans -

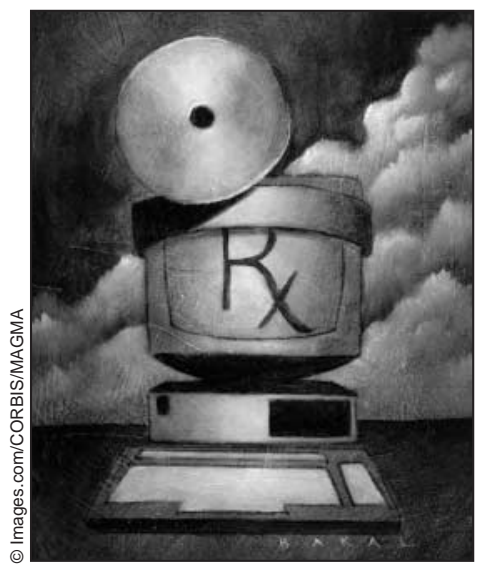

A drugstore near you.
Despite the fault-seeking missions of US regulators, the safety and quality of Canadian drugs cannot be the core of this issue. 
have thus far not sought large undisclosed discounts from manufacturers. However, because Canada's system of drug coverage is a loose patchwork, as in the US, if provinces increasingly negotiate such discounts we can expect a US-style outcome. That is, any hidden discount, including "price-volume agreements," between provinces and manufacturers will place upward pressure on the retail prices borne out-ofpocket. Uninsured or underinsured Canadians would thereby be subsidizing the drug purchases made by their own governments (not to mention those of the large US purchasers).

Canadian Internet pharmacy is a controversy because it creates a transparent escape route for Americans who feel pricegouged in their own country. One effect of this is strong upward pressure on Canadian retail prices. The optimal policy response for Canadians is un- clear. Banning exportation of prescription drugs from Canadian dispensaries might take pressure off Canadian drug prices in the short term, but international trends suggest that it would not remove the longterm upward pressures. Progressively more countries are negotiating various forms of confidential price discounts, placing upward pressure on global "list" prices for drugs. Canada's provincial governments could follow suit by negotiating their own discounts. To mitigate the adverse effects of inflated Canadian "retail" prices, provinces could create mechanisms to "share" savings with cash-paying consumers. Alternatively, governments could negotiate concealed discounts while expanding public pharmacare such that no Canadian bears excessive out-ofpocket drug costs, however inflated "retail" prices may be. It is increasingly likely that Cana- dians will soon face this difficult policy dilemma. We only hope that policy-makers and the public do not forget that secret price discounts also come with hidden costs.

Steven Morgan

Centre for Health Services and

Policy Research, and

Department of Health Care and

Epidemiology

University of British Columbia

Vancouver, BC

Jeremiah Hurley

Centre for Health Economics and

Policy Analysis

Department of Economics

McMaster University

Hamilton, Ont.

\section{References}

1. Danzon P, Furukawa MF. Prices and availability of pharmaceuticals: evidence from nine countries. Health Aff [Web Exclusive]; Oct 2003. Available: http://content.healthaffairs.org/cgi/co ntent/full/hlthaff.w3.521v1/DC1 (accessed 2004 Feb 23)

2. Reforming States Group. State initiatives on prescription drugs: creating a more functional market. Health Aff (Millwood) 2003;22(4):128-36.

\section{Pharmaceutical Industry}

\section{Internet pharmacy: the tug-of-war intensifies}

$\mathrm{A}^{1}$ larmed by the growing reimportation of prescription drugs back into the United States from Canada, American pharmaceutical manufacturers are trying to curb attempts by state and city governments to make large-scale purchases of cheaper medications. In doing so they have raised the spectre of shortages in Canada's domestic drug supply and have triggered charges that they are violating antitrust laws for the purpose of "protecting their profits."

Lured by prices that can be $70 \%$ cheaper, more than one million Americans buy their drugs from Canadian pharma-

a cies at an estimated value of more than US\$1 billion.

The US Department of Justice and several state pharmacy regulators have filed suits against some US-based stores $\stackrel{\circ}{\vec{G}}$ and Web sites that process sales through Canadian pharmacies,

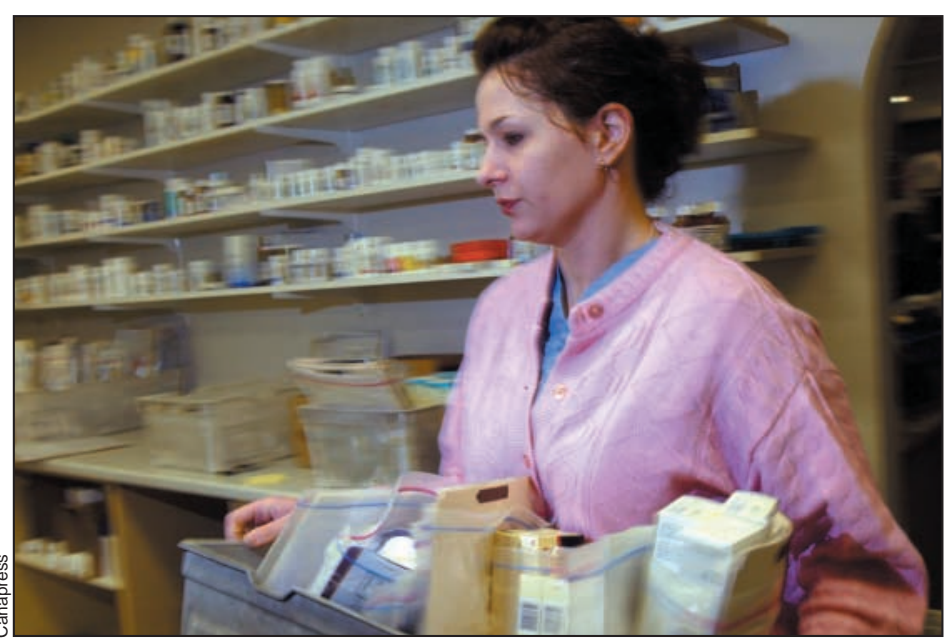

US drug manufacturers and regulators hope to curb drug reimportation through online pharmacies, such as this one based in Calgary.

but most have continued operating. There have been no suits against Canadian-based Web sites or pharmacies operating in Canada.

As the cross-border market grows, US drug manufacturers and pharmacists have become increasingly concerned about their loss of domestic sales, while US federal authorities have expressed safety concerns.

The FDA has repeatedly conducted surveillance operations to confirm the dangers of drug importation from Canada. 